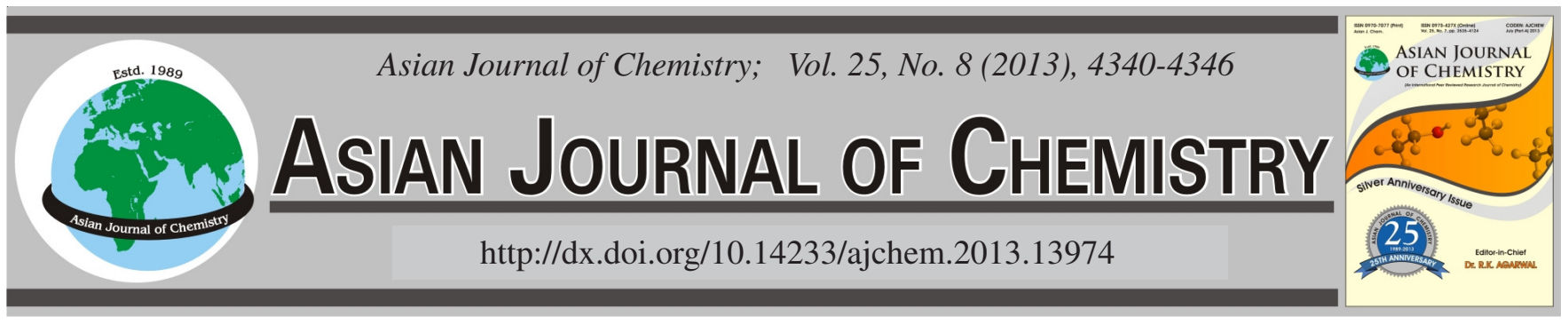

\title{
Modeling of Nitrate Removal by Nanosized Iron Oxide Immobilized on Perlite Using Artificial Neural Network
}

\author{
A. KHANI ${ }^{1, *}$ and A. NemATI ${ }^{2}$
}

${ }^{1}$ Department of Chemistry, Miyaneh Branch, Islamic Azad University, Miyaneh, Iran

${ }^{2}$ Department of Electrical and Electronic Engineering, Miyaneh Branch, Islamic Azad University, Miyaneh, Iran

*Corresponding author: E-mail: a.khani59@yahoo.com

(Received: 27 April 2012;

Accepted: 11 February 2013)

AJC-12960

The removal of nitrate from aqueous solution by adsorption process onto nanosized iron oxide immobilized on perlite (nIO-P) is novel, effective and easy way. In this work, the effective parameters on removal of nitrate by adsorption process, which included the amount of nIO-P $(\mathrm{m})$, initial concentration of nitrate $\left(\mathrm{C}_{0}\right)$, contact time, $\mathrm{pH}$ and temperature $(\mathrm{T})$, were investigated. It was found that the content of adsorption followed decreasing order: $\mathrm{m}=8>4>2>1 \mathrm{~g}, \mathrm{C}_{0}=20>25>15>10 \mathrm{mg} \mathrm{L}^{-1}, \mathrm{pH}=5>7>8>9$ and $\mathrm{T}=45>35>25>15$ ${ }^{\circ} \mathrm{C}$. The three-layered feed forward back propagation neural network was used for modeling of nitrate adsorption on nIO-P. The comparison between the predicted results of the designed artificial neural network (ANN) model and the experimental data proved that modeling of nitrate adsorption process using artificial neuron network was a good and precise method to predict the extent of adsorption of nitrate on adsorbent under different conditions.

Key Words: Modeling, Artificial neural network, Nanosized iron oxide, Water treatment, Nitrate.

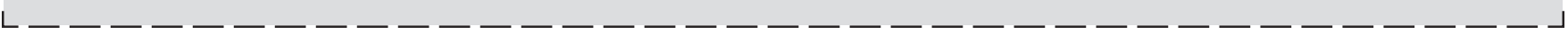

\section{INTRODUCTION}

High concentrations of $\mathrm{N}$-containing compounds in drinking water cause health problems such as cyanosis among children and cancer of the alimentary canal. Therefore, removal of nitrate from water samples by universal adsorption process is of significant important from the health and environmental point of view $^{1}$. Nitrate is mainly found in most of natural waters at moderate concentrations but is often enriched to over the contaminant levels from the excessive using of fertilizers and uncontrolled discharge of raw fertilizers ${ }^{2}$. A number of techniques, namely coagulation, precipitation, filtration, reverse osmosis, ion exchange and adsorption have been used to remove toxic elements and etc., from aquatic environment ${ }^{3-8}$.

In numerous investigations, an aqueous suspension of the adsorbent particles has been used ${ }^{9,10}$. However, the use of suspensions requires separation and recycling of the ultra fine adsorbents from the treated liquid and can be an inconvenient, time-consuming and expensive process. The key to the probem of industrializing the technology seems to be simple and low cost immobilization of adsorbents on solid media suitable for the treatment process.

The perlite is a good base in immobilization process for its merits including high porosity, low density, natural abundance, the absence of toxicity and low cost ${ }^{11}$. Mostafa et al. ${ }^{3}$ studied the adsorption of arsenate from aqueous solution by iron oxide-coated perlite (IOCP).

Artificial neural network (ANN) is a promising alternative modeling technique. One of the characteristics of modeling based on artificial neural networks is that it does not require the mathematical description of the phenomena involved in the process and might therefore prove useful in simulating and up-scaling complex adsorption systems. The success in obtaining a reliable and robust network depends strongly on the choice of process variables involved as well as the available set of data and the domain used for training purposes ${ }^{12}$. Therefore, in the present paper, the modeling of nitrate adsorption onto synthesized nanosized iron oxide immobilized on perlite using artificial neural network has been studied.

\section{EXPERIMENTAL}

The expended perlite (EP) used in the present study was obtained from Goohar Sahand Co. (Iran). Its chemical composition and properties are shown in Table-1. Sodium nitrate, $\mathrm{FeCl}_{3} \cdot 6 \mathrm{H}_{2} \mathrm{O}, \mathrm{NaOH}$ and $\mathrm{H}_{2} \mathrm{SO}_{4}$ were obtained from Merck Co. (Germany). Deionized distilled water was used in all experiments and all experiments were repeated twice [variance $\left(\sigma^{2}\right)$ $=0.002]$.

Preparation of nanosized iron oxide immobilized on perlite (nIO-P): Perlite was soaked in $\mathrm{H}_{2} \mathrm{SO}_{4}$ solution at $\mathrm{pH} 1$ 


\begin{tabular}{cc}
\hline \multicolumn{3}{c}{ TABLE-1 } \\
CHEMICAL COMPOSITION AND \\
PROPERTIES OF EXPANDED PERLITE \\
\hline \multicolumn{3}{c}{ Constituent } \\
\hline \multicolumn{3}{c}{$81,11.4,4.3,0.9,0.8,0.7,0.6}$, \\
$\mathrm{SiO}_{2}, \mathrm{Al}_{2} \mathrm{O}_{3}, \mathrm{~K}_{2} \mathrm{O}, \mathrm{CaO}, \mathrm{Na}_{2} \mathrm{O}, \quad 0.2,0.1$ (percentage $\left.(\mathrm{Wt} \%)\right)$ \\
$\mathrm{Fe}_{2} \mathrm{O}_{3}, \mathrm{MgO}, \mathrm{MnO}_{2}$ & White \\
\hline \multicolumn{3}{c}{ Properties } \\
\hline Colour & 7 \\
pH & $5-5.5 \mathrm{~m}^{2} \mathrm{~g}^{-1}$ \\
Specific area & $1300^{\circ} \mathrm{C}$ \\
Melting point & $3 \mathrm{~g} / \mathrm{cm}^{3}$ \\
Density & Globular \\
Granule shape & No soluble \\
Solubility in water &
\end{tabular}

for $24 \mathrm{~h}$ and then rinsed 3 times with deionized water and dried in an oven at $105 \pm 1{ }^{\circ} \mathrm{C}$ for another $24 \mathrm{~h}$. Thus the perlite with acidic treatment was used for coating application. The solution of $\mathrm{Fe}$ (III) was prepared by dissolving reagent grade $\mathrm{FeCl}_{3} \cdot 6 \mathrm{H}_{2} \mathrm{O}$ in deionized water. The $\mathrm{Fe}(\mathrm{III})$ solution was taken in a beaker, stirring with a magnetic stirrer at $200 \mathrm{rpm}$ and added with $0.5 \mathrm{M} \mathrm{NaOH}$ solution until $\mathrm{pH}$ at $9.5 \pm 0.1$ and the Fe(III) solution was continued to mix for $5 \mathrm{~min}$. Subsequently the mixed solution was poured into $100 \mathrm{~g}$ perlite in a conical flask and then it was placed in a temperature-controlled shaker at $60 \pm 1{ }^{\circ} \mathrm{C}$ at $200 \mathrm{rpm}$ for $24 \mathrm{~h}$ and finally it was dried in an oven at $105 \pm 1{ }^{\circ} \mathrm{C}$ for $24 \mathrm{~h}$. After that, the sample was washed 5 times with deionized water and finally dried at $60 \pm$ $1{ }^{\circ} \mathrm{C}^{3}$.

Characterization of nIO-P: The particle size of synthesized iron oxide was determined using XRD pattern of the nIO-P ${ }^{13,14}$. Morphology of the prepared nIO-P was determined using a Leo 440i scanning electron microscope (SEM) followed by AU-coated by sputtering method using a coater sputter SC 761 (Fig. 1).

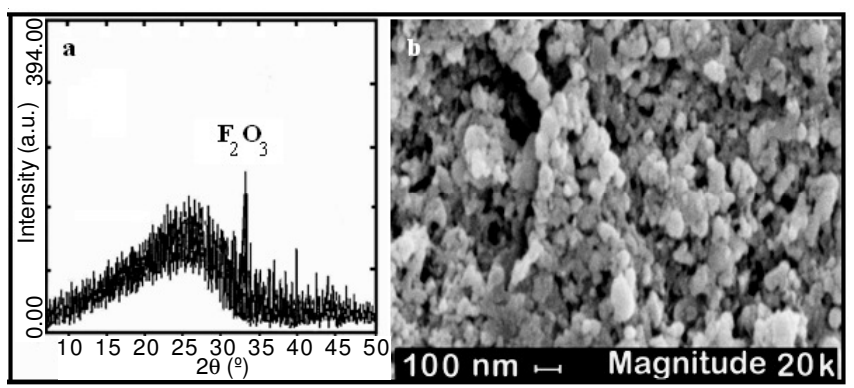

Fig. 1. XRD pattern (a) and SEM image (b) of nIO-P

Batch experiments of nitrate adsorption: Batch adsorption of nitrate was carried out in a $200 \mathrm{~mL}$ Pyrex conical flask in basic condition containing $2 \mathrm{~g}$ nIO-P adsorbent in the 100 $\mathrm{mL}$ reaction solution. The initial nitrate solution concentration $20 \mathrm{mg} \mathrm{L}^{-1}$ was used. The $\mathrm{pH}$ of the solution was adjusted using $0.1 \mathrm{M} \mathrm{HCl}$ and $0.1 \mathrm{M} \mathrm{NaOH}$ solutions during the adsorption study. The samples were collected at different intervals of time from 1-90 min. The solutions were shaken at $200 \mathrm{rpm}$ in a temperature-controlled shaker with the temperature at $25 \pm$ $1{ }^{\circ} \mathrm{C}$. Finally, collected samples were centrifuged in a high speed centrifuge and filtered. The concentrations of nitrate in the samples were determined by UV-visible spectroscopy using spectrophotometer (DR5000) at $\lambda_{\max }=215 \mathrm{~nm}$.
Artificial neural network software: All ANN calculations carried out using Matlab 6.5 mathematical software with ANN toolbox for windows running on personal computer (Pentium IV $2800 \mathrm{MHz}$ ). A three-layer network with a sigmoidal transfer function with back propagation algorithm was designed in this study.

\section{RESULTS AND DISCUSSION}

Artifical neural network modeling: ANNs are direct inspiration from the biology of human brain, where billions of neurons are interconnected to process a variety of complex information. Accordingly, a computational neural network consists of simple processing units called neurons ${ }^{15,16}$. In general, a neural net (multilayered perceptron) (Fig. 2), is parallel interconnected structure consisting of: (1) input layer of neuron (independent variables), (2) a number of hidden layers, (3) and output layer (dependent variables).

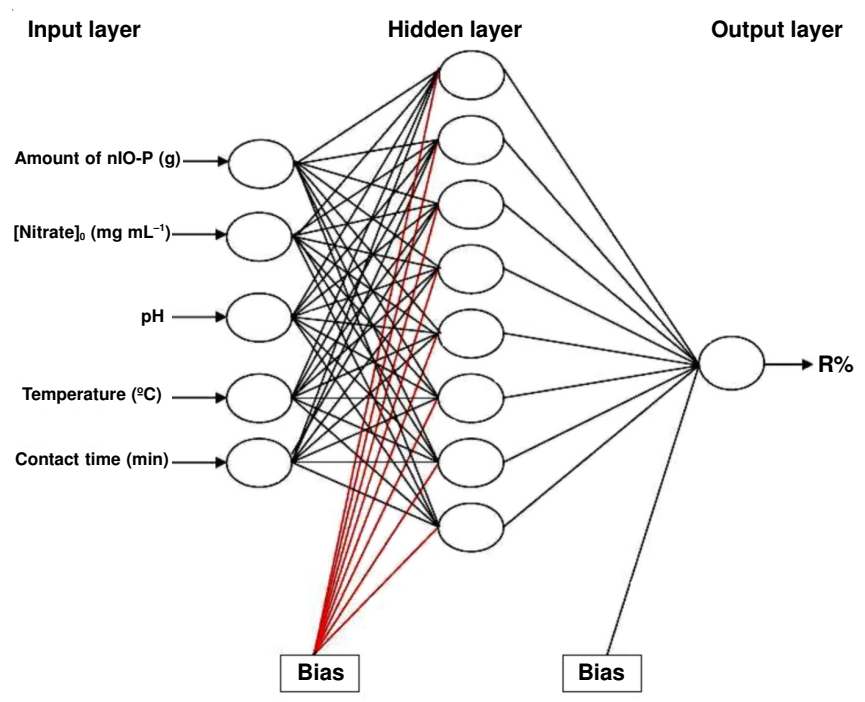

Fig. 2. Artifical neural network optimized structure

The number of input and output neurons is fixed by the nature of the problem. The hidden layers act like feature detectors there can be more than one hidden layer. Universal approximation theory, however, suggests that a network with a single hidden layer with a sufficiently large number of neurons can interpret any input-output structure ${ }^{17}$.

The topology of an artificial neural network (ANN) is determined by the number of layers in the ANN, the number of nodes in each layer and the nature of the transfer functions. Correct identification of the set of independent input variables and the output variables is the first task in building ANN model for a process. Optimization of ANN topology is probably the next important step in the development of a model. It is recognized that the selection of neurons in the hidden layer can have a significant effect on network performance. In this study, different numbers of neurons, from 2-14, in the hidden layer was tested. Fig. 3 illustrates the relation between the network error and the number of neurons in the hidden layer. The mean square error (MSE) was used as the error function. The mean square error measures the network's performance according to the following equation ${ }^{1,18}$ : 


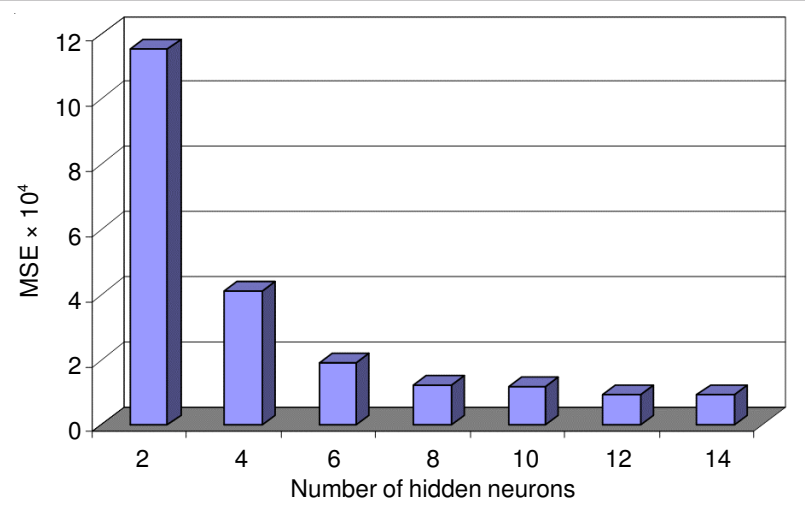

Fig. 3. Effect of the number of neurons in hidden layer on the performance of the artifical neural network

$$
\text { Mean square error }(\mathrm{MSE})=\frac{1}{\mathrm{Q}} \sum_{\mathrm{i}=1}^{\mathrm{Q}}\left(\mathrm{y}_{\mathrm{i}, \mathrm{nn}}-\mathrm{y}_{\mathrm{i}, \mathrm{exp}}\right)^{2}
$$

where $\mathrm{Q}$ is the number of data point, $\mathrm{y}_{\mathrm{i}, \mathrm{nn}}$ is the network prediction and $\mathrm{y}_{\mathrm{i}, \text { exp }}$ is experimental response and $\mathrm{i}$ is an index of data. We can see that the performance of the network stabilized after inclusion of an adequate number of hidden units just about eight (Fig. 3). The network with too few neurons in the hidden layer cannot converge effectively. We used three layered feed forward back propagation neural network (5:8:1) for modeling of adsorption process (Fig. 2).

In the present work, the input variables to the feed forward neural network were as follows: the amount of nIO-P $(\mathrm{g})$, initial concentration of nitrate $\left(\mathrm{mg} \mathrm{L}^{-1}\right)$, contact time $(\mathrm{min})$, initial $\mathrm{pH}$ and temperature $\left({ }^{\circ} \mathrm{C}\right)$. The percentage of nitrate removal ( $\mathrm{R} \%$ ) was chosen as the experimental response or output variable:

$$
\mathrm{R}(\%)=\frac{[\text { Nitrate }]_{0}-[\text { Nitrate }]}{[\text { Nitrate }]_{0}} \times 100
$$

where $[\text { Nitrate }]_{0}$ was the initial concentration of nitrate $\left(\mathrm{mg} \mathrm{L}^{-1}\right)$ and [Nitrate] was the concentration of nitrate $\left(\mathrm{mg} \mathrm{L}^{-1}\right)$ at time $\mathrm{t}$. The sigmoidal transfer function was used as a transfer function in the hidden and output layers. This is the most widely used transfer function, which is given by:

$$
f(x)=\frac{1}{1+\exp (-x)}
$$

where $f(x)$ is the hidden neuron output ${ }^{1}$. The training function was Train Scaled Conjugate Gradient (trainscg). Out of the several data points generated, 468 experimental sets were used to develop the ANN model. The range of variables studied is summarized in Table-2.

\begin{tabular}{lc}
\multicolumn{2}{c}{ TABLE-2 } \\
\multicolumn{2}{c}{ MODEL VARIABLES AND THEIR RANGES } \\
\hline \multicolumn{2}{c}{ Variable } \\
\hline \multicolumn{2}{c}{ Input layer } \\
\hline Amount of nIO-P $(\mathrm{g})$ & $1-10$ \\
Initial concentration of nitrate $\left(\mathrm{mg} \mathrm{L}^{-1}\right)$ & $10-25$ \\
$\mathrm{pH}$ & $1-10$ \\
Temperature $\left({ }^{\circ} \mathrm{C}\right)$ & $25-55$ \\
Contact time (min) & $0-90$ \\
\hline \multicolumn{2}{c}{ Output layer } \\
\hline Nitrate removal per cent $(\mathrm{R} \%)$ & $0-100$ \\
\hline
\end{tabular}

The samples were split into training, validation and test subsets that each of them contains 234, 117 and 117 samples, respectively. The validation and test sets, used for evaluation of the validation and modeling power of the model, were randomly selected from the experimental data. Since the used transfer function in the hidden layer was sigmoid, all samples were scaled in the range of 0.2-0.8. So any samples of the training, validation and test sets $\left(\mathrm{X}_{\mathrm{i}}\right)$ were scaled to a new value $\mathrm{x}_{\mathrm{i}}$ as follows:

$$
\mathrm{x}_{\mathrm{i}}=0.2+\frac{0.6\left(\mathrm{X}_{\mathrm{i}}-\min \left(\mathrm{X}_{\mathrm{i}}\right)\right)}{\max \left(\mathrm{X}_{\mathrm{i}}\right)-\min \left(\mathrm{X}_{\mathrm{i}}\right)}
$$

where $\min \left(\mathrm{X}_{\mathrm{i}}\right)$ and $\max \left(\mathrm{X}_{\mathrm{i}}\right)$ are the extreme values of the input variables $\left(\mathrm{X}_{\mathrm{i}}\right)^{1}$.

In order to calculate training, validation and test errors all of the outputs were performed an inverse range scaling to return the predicted responses to their original scale and compared them with experimental responses. Fig. 4 shows a comparison between calculated and experimental values of the output variable ( $\mathrm{R} \%$ ) for test set, using the neural network model with number of hidden layer equal to 8 . In order to show the success of the prediction two lines was used.

The first one is the perfect fit (predicted data equal to experimental data), on which all the data of an ideal model should lay. The other line is the line that best fits on the data of the scatter plot with equation $\mathrm{Y}=\mathrm{ax}+\mathrm{b}$ and it is obtained with regression analysis based on the minimization of the squared errors. The correlation coefficient of this line is also presented $\left(\mathrm{R}^{2}\right)$. The closer to 1 this factor is and the closer the coefficients of the line to 1 and 0 , respectively, are the better the model is. The plot in this figure has correlation coefficient of 0.991 for the test set. These results confirm that the neural network model reproduces the adsorption in our process, within the experimental ranges adopted in the model fitting.

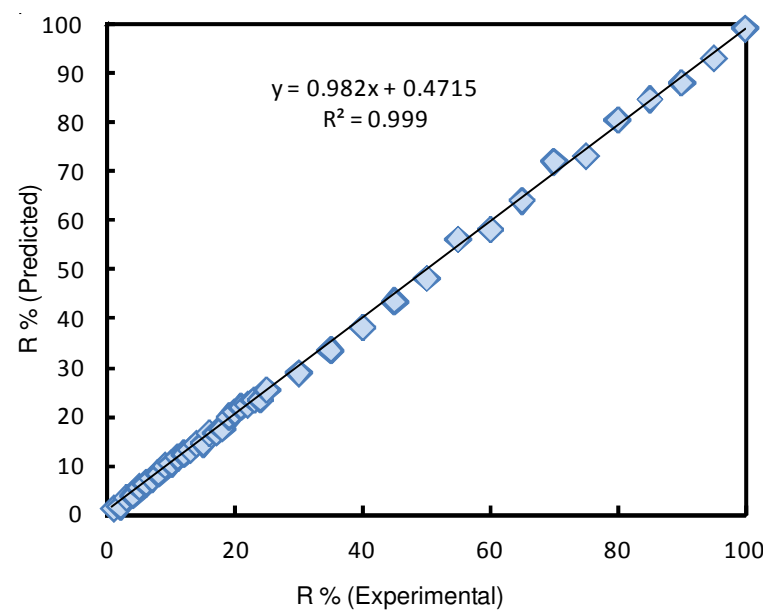

Fig. 4. Comparison of the experimental results with those calculated via artificial neural network modeling for test set

Effect of contact time on the efficiency of nitrate adsorption on nIO-P: Naturally, contact time influences the efficiency of the adsorption process. Fig. 5 shows the relationship between the removal efficiency of nitrate and the contact time in basic condition (basic condition: solution volume of nitrate $\left.(\mathrm{V})=100 \mathrm{~mL}, \mathrm{~m}=2 \mathrm{~g}, \mathrm{C}_{0}=20 \mathrm{mg} \mathrm{L}^{-1}, \mathrm{pH}=7, \mathrm{~T}=25^{\circ} \mathrm{C}\right)$. 
Also, this figure shows fair agreement between predictions from the ANN model and experimental results. From this plot it can be seen that obtained results from the proposed ANN model are in good agreement with the experimental data. The Fig. 4 as a sample is the one of the experimental conditions that shows fair agreement between predictions from the ANN model and experimental results. From this plot it can be seen that obtained results from the proposed ANN model are in good agreement with the experimental data.

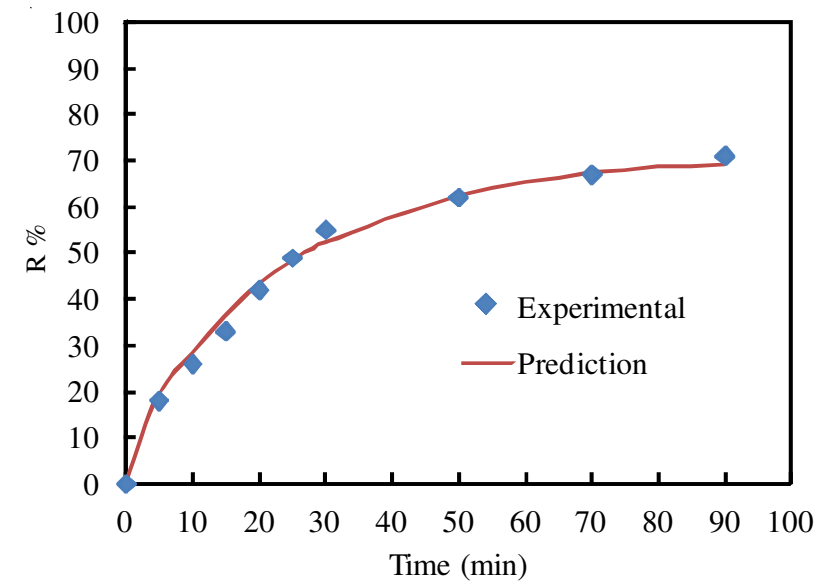

Fig. 5. Comparison between artificial neural network predicted and experimental values of $\mathrm{R} \%$ as a function of contact time in basic condition

Effect of the amount of nIO-P: In order to make a comparative study for adsorption of nitrate in the presence of different amounts of nIO-P (m), the other effective parameters were kept constant in basic condition. The changes in the percentage removal of nitrate $v s$. amount of nIO-P are shown in Fig. 6. According to this figure removal per cent of nitrate increases with an increase in the amount of nIO-P as $\mathrm{m}=8>$ $4>2>1 \mathrm{~g}$. The reason of this observation is thought to be the fact that with increasing amount of adsorbent surface, the extent of adsorption becomes higher ${ }^{1}$. This observation can be explained in terms of availability of active sites on nIO-P surface. The total active surface area increases with increasing nIO-P dosage. Fig. 6 shows the predicted R \% estimated from the ANN model (solid line) and experimental ones as a function of contact time in the presence of different amounts of nIO-P. It can be seen that the ANN model correctly predicts the trend of $\mathrm{R} \%$.

Effect of initial nitrate concentration: The initial concentrations of nitrate were $10,15,20$ and $25 \mathrm{mg} \mathrm{L}^{-1}$ and the other effective parameters were kept constant in basic condition. The changes in the removal percentage of nitrate during the adsorption on nIO-P are shown in Fig. 7. A clear distinction can be seen at the end of $90 \mathrm{~min}$ as $\mathrm{C}_{0}=20>25>15>10 \mathrm{mg}$ $\mathrm{L}^{-1}$. Indeed, experiments performed with different concentrations of nitrate showed that the removal percentage of nitrate increases with an increase in nitrate concentration up to 20 $\mathrm{mg} \mathrm{L}^{-1}$ and is then decreased. The presumed reason is that when the initial concentration of nitrate is increased, more and more nitrate ions are adsorbed on the surface of nIO-P ${ }^{1}$. The large amount of adsorbed nitrate is thought to have an inhibitive effect on the adsorption of nitrate ions on nIO-P,
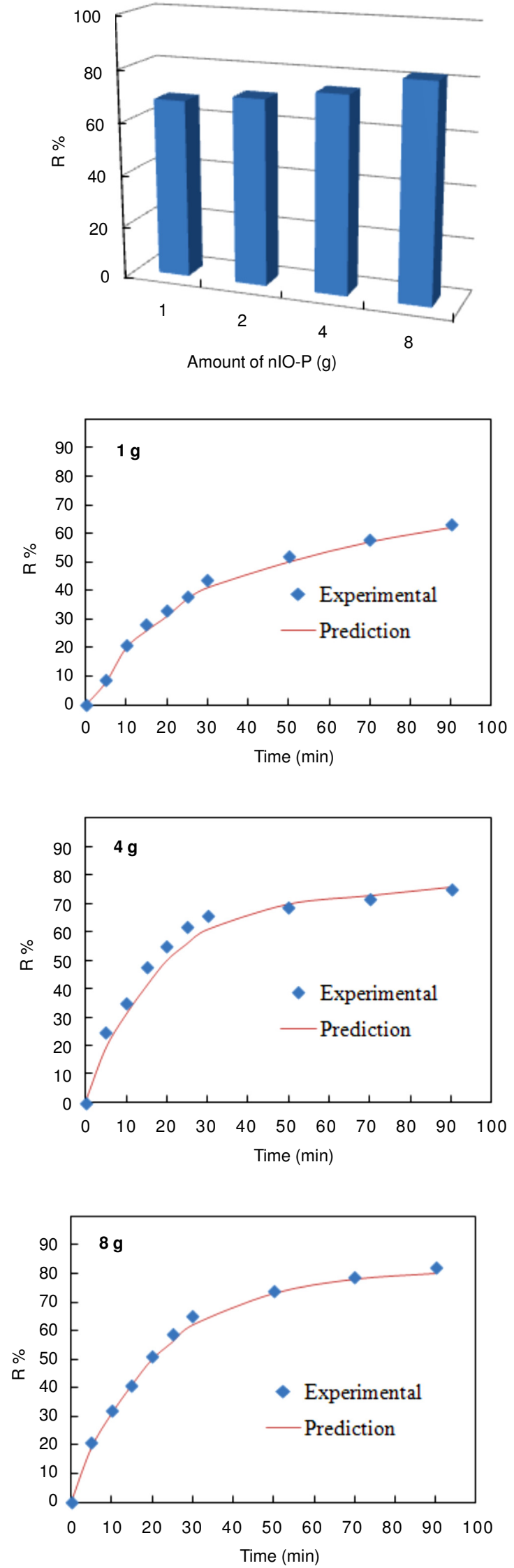

Fig. 6. Effect of the amount of nIO-P on the percentage removal of nitrate $($ time $=90 \mathrm{~min})$ and comparison between ANN predicted and experimental values of $\mathrm{R} \%$ as a function of contact time in the presence of different amounts of nIO-P (V $=100 \mathrm{~mL}, \mathrm{C}_{0}=20 \mathrm{mg} \mathrm{L}^{-1}$, $\mathrm{pH}=7, \mathrm{~T}=25^{\circ} \mathrm{C}$ ) 

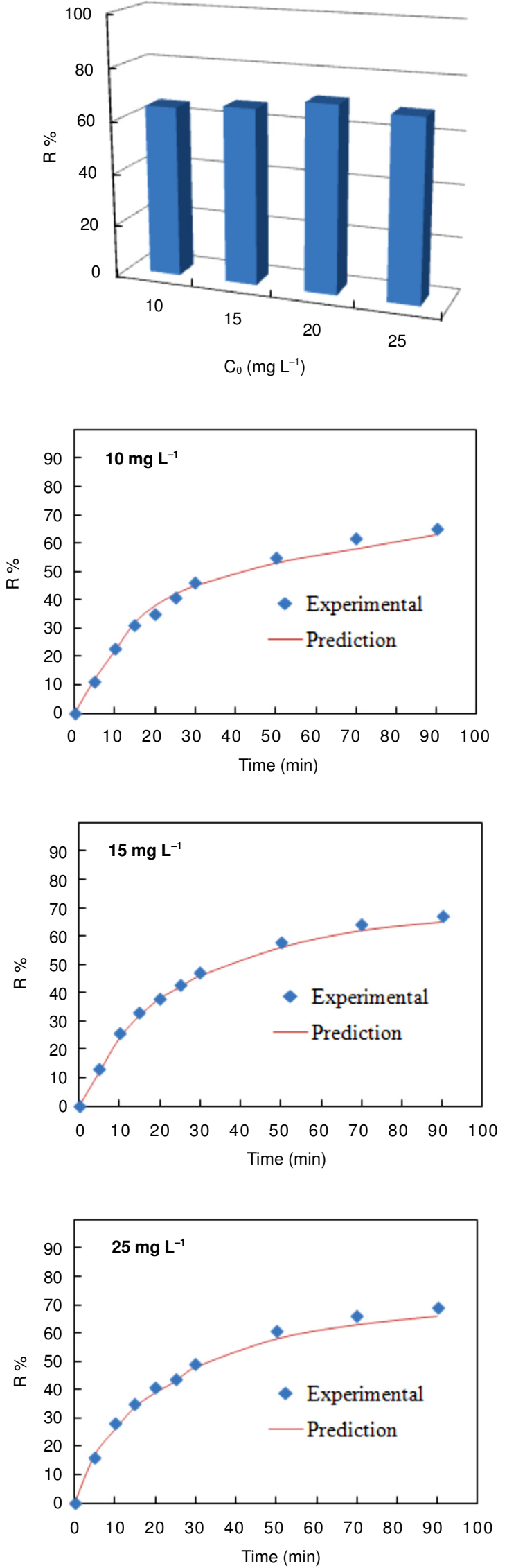

Fig. 7. Effect of initial concentration on the percentage removal of nitrate (time $=90 \mathrm{~min}$ ), and comparison between ANN predicted and experimental values of $\mathrm{R} \%$ as a function of contact time at different initial concentration of nitrate $(\mathrm{V}=100 \mathrm{~mL}, \mathrm{~m}=2 \mathrm{~g}, \mathrm{pH}=7, \mathrm{~T}=$ $\left.25^{\circ} \mathrm{C}\right)$ because of the lack of any direct contact between them. This figure also, shows the predicted $\mathrm{R} \%$ estimated from the ANN model (solid line) and experimental ones as a function of contact time at different initial concentration of nitrate. It can be seen that the ANN model correctly predicts the trend of removal percentage of nitrate.

Adsorption behaviour of nitrate at different pH: The $\mathrm{pH}$ of solution has an important role in ions adsorption process on adsorbents. The negative surface charge of perlite samples increased with an increase in $\mathrm{pH}$. Electro-kinetic studies have also shown that the perlite samples have no iso-electric point and have negative zeta potential and surface charge. The variation of surface charge density of perlite samples with increasing $\mathrm{pH}$ can be result in the ionization of surface silanol groups ${ }^{19}$. The effect of $\mathrm{pH}$ on adsorption of nitrate was examined at different $\mathrm{pH}$ ranging from 5-9. Our results showed that the adsorption efficiency decreases with an increase in $\mathrm{pH}$ (Fig. 8). The reason of these observations may be attributed to the increasing of negative surface charge of nIO-P with $\mathrm{pH}$.

Adsorption behaviour of nitrate at different temperatures: The changes in concentration of nitrate with time during the adsorption process at each temperature are shown in Fig. 9. The differences in the adsorption efficiency of nitrate were small. These small differences should originate from the effect of energy of reaction ${ }^{1}$. Removal percentage increases as temperature increases from $15-45^{\circ} \mathrm{C}$.
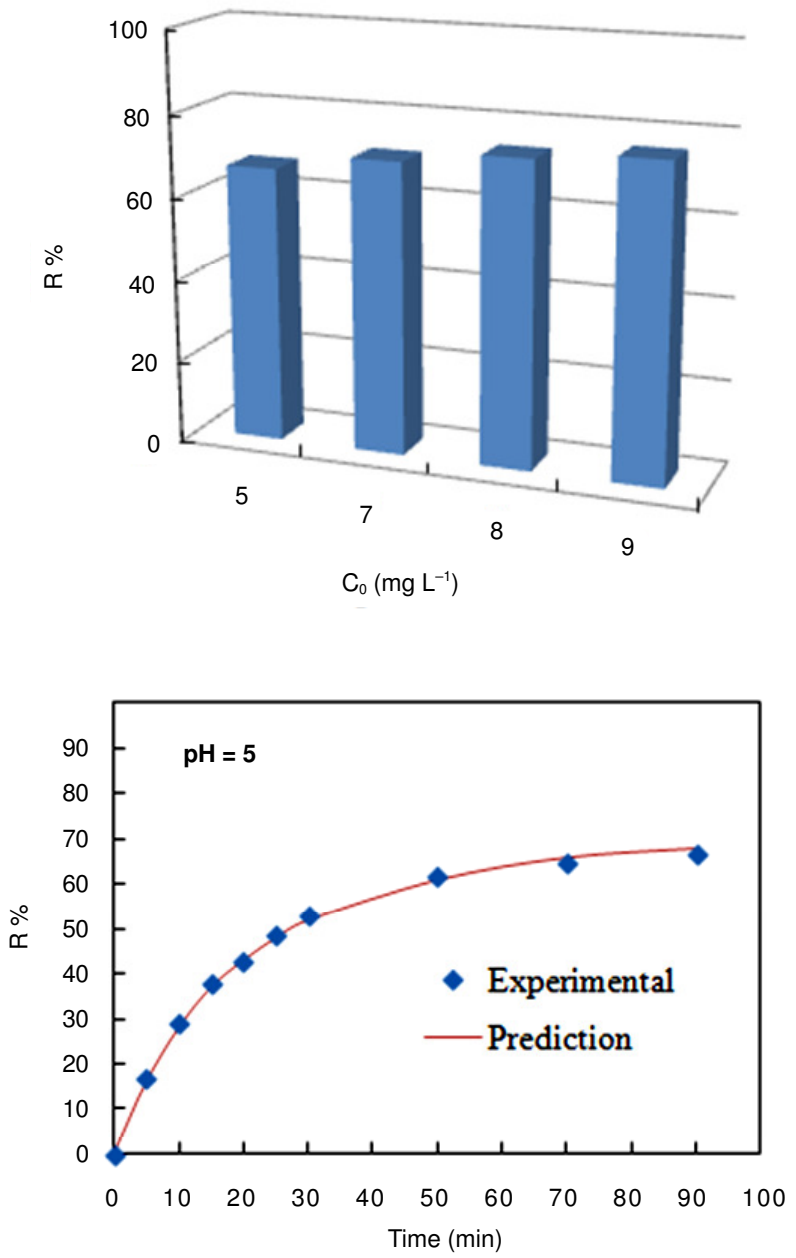

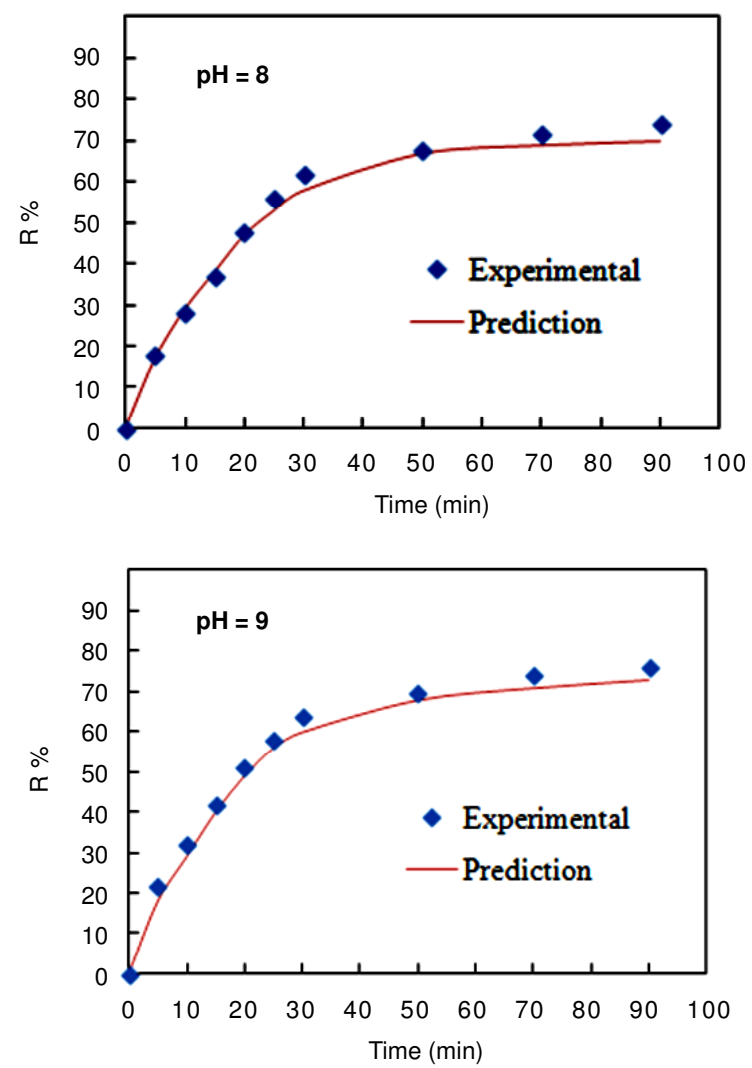

Fig. 8. Effect of $\mathrm{pH}$ on the percentage removal of nitrate (time $=90 \mathrm{~min}$ ) and comparison between ANN predicted and experimental values of $\mathrm{R} \%$ as a function of contact time at different $\mathrm{pHs}(\mathrm{V}=100 \mathrm{~mL}, \mathrm{~m}$ $\left.=2 \mathrm{~g}, \mathrm{C}_{0}=20 \mathrm{mg} \mathrm{L}^{-1}, \mathrm{~T}=25^{\circ} \mathrm{C}\right)$

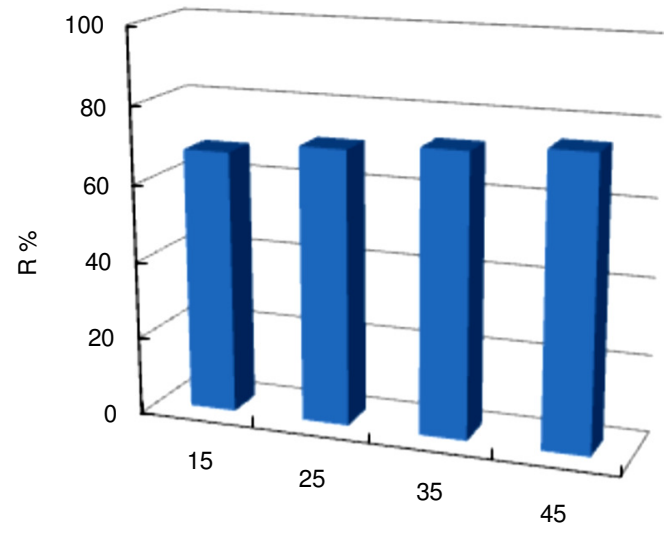

Temperature $\left({ }^{\circ} \mathrm{C}\right)$

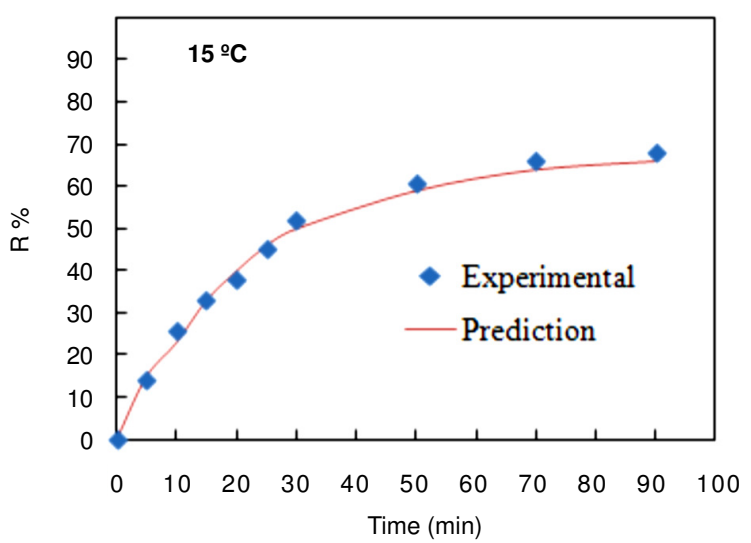

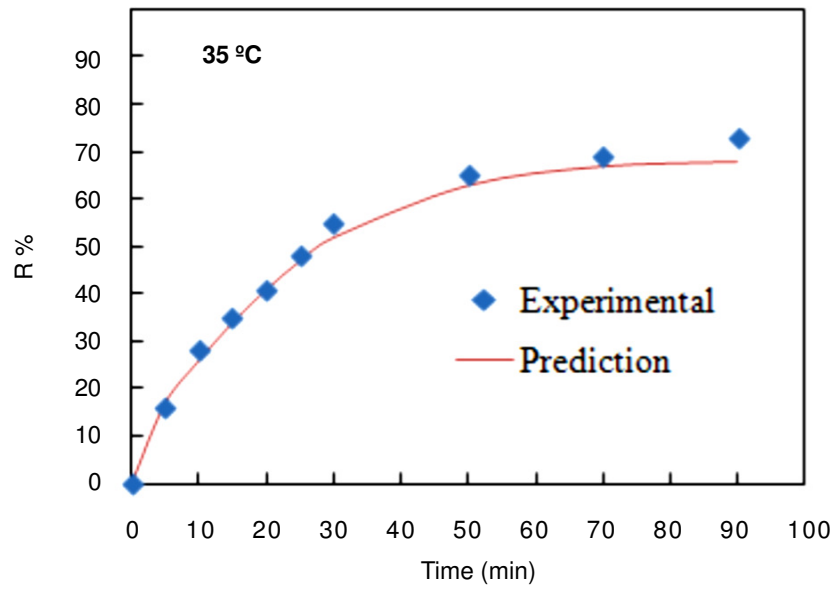

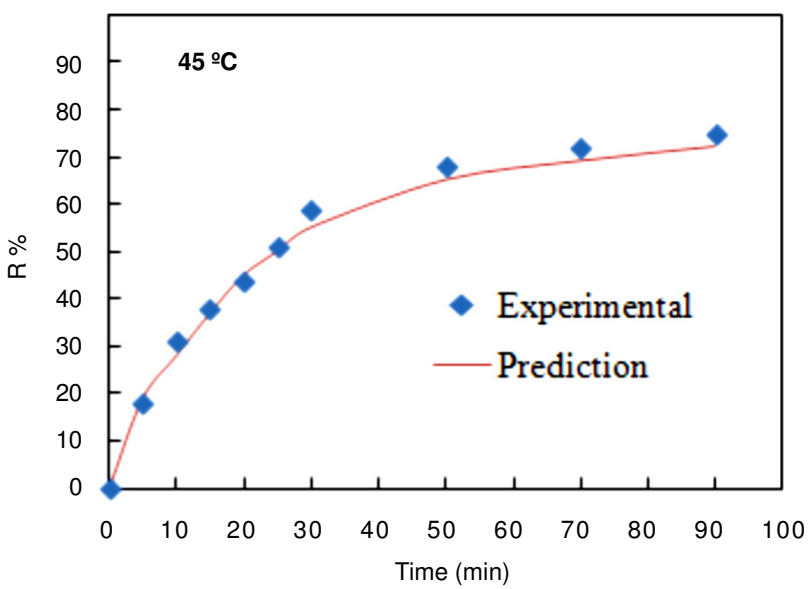

Fig. 9. Effect of temperature on the percentage removal of nitrate (time $=$ $90 \mathrm{~min}$ ) and comparison between ANN predicted and experimental values of $\mathrm{R} \%$ as a function of contact time at different temperatures $\left(\mathrm{V}=100 \mathrm{~mL}, \mathrm{~m}=2 \mathrm{~g}, \mathrm{C}_{0}=20 \mathrm{mg} \mathrm{L}^{-1}, \mathrm{pH}=7\right)$

\section{Conclusion}

The result showed that nitrate could be removed significantly from aqueous solution by adsorption onto the nIO-P in experimental conditions. The effect of various operational parameters on nitrate removal efficiency was investigated. Present results also showed that the content of adsorption followed decreasing order: amount of nIO-P $(\mathrm{m})=8>4>2>$ $1 \mathrm{~g}$, initial concentration of nitrate $\left(\mathrm{C}_{0}\right)=20>25>15>10$ $\mathrm{mg} \mathrm{L}^{-1}, \mathrm{pH}=5>7>8>9$ and temperature $(\mathrm{T})=45>35>25$ $>15{ }^{\circ} \mathrm{C}$. Artificial neural network modeling has been successfully used to investigate the cause effect relationship in the adsorption process. The ANN model could describe the behaviour of the complex interaction process with the range of experimental conditions adopted. Simulation based on the ANN model can estimate the behaviour of the process under different conditions.

\section{ACKNOWLEDGEMENTS}

The authors expressed their gratitude to Miyaneh Branch, Islamic Azad University for the financial support and assistance in the research project. 


\section{REFERENCES}

1. A.R. Khataee and A. Khani, Int. J. Chem. React. Eng., 7, 1 (2009).

2. Y. Cengeloglu, A. Tor, M. Ersoz and G. Arslan, Sep. Purif. Technol., 51, 374 (2006)

3. M.G. Mostafa, Y.-H. Chen, J-S. Jean, C-C. Liu and Y.-C. Lee, J. Hazard. Mater., 187, 89 (2011)

4. A. Demirbas, J. Hazard. Mater., 157, 220 (2008)

5. D. Sud, G. Mahajan and M.P. Kaur, Bioresour. Technol., 99, 6017 (2008).

6. S.P. Singh, L.Q. Ma and M.J. Hendry, J. Hazard. Mater., 136, 654 (2006).

7. V.K. Gupta, V.K. Saini and N. Jain, J. Colloid Interf. Sci., 288, 55 (2005).

8. G. Zhang, J. Qu, H. Liu, R. Liu and R. Wu, Water Res., 41, 1921 (2007).

9. L.A. Zeng, Water Res., 37, 4351 (2003).

10. T.L. Theis, R. Iyer and S.K. Ellis, J. AWWA, 84, 101 (1992).

11. S.N. Hosseini, S.M. Borghei, M. Vossoughi and N. Taghavinia, Appl. Catal. B, 74, 53 (2007).
12. N. Daneshvar, A.R. Khataee and N. Djafarzadeh, J. Hazard. Mater., 137, 1788 (2006).

13. L. Alidokht, A.R. Khataee, A. Reyhanitabar and S. Oustan, Desalination, 270, 105 (2011).

14. N. Daneshvar, M.H. Rasoulifard, A.R. Khataee and F. Hosseinzadeh, J. Hazard. Mater., 143, 95 (2007).

15. V.K. Pareek, M.P. Brungs, A.A. Adesina and R. Sharma, J. Photochem. Photobiol. A, 149, 139 (2002).

16. C.A. Gontarski, P.R. Rodrigues, M. Mori and L.F. Prenem, Comp. Chem. Eng, 24, 1719 (2000).

17. D. Salari, N. Daneshvar, F. Aghazadeh and A.R. Khataee, J. Hazard. Mater., 125, 205 (2005).

18. A. Aleboyeh, M.B. Kasiri, M.E. Olya and H. Aleboyeh, Dyes Pigm., 77, 288 (2008).

19. H. Ghassabzadeh, M. Torab-Mostaedi, A. Mohaddespour, M. Ghannadi Maragheh, S.J. Ahmadi and P. Zaheri, Desalination, 261, 73 (2010). 